УДК 691.328.44

\title{
ДОСЛІДЖЕННЯ ВПЛИВУ ХІМІЧНИХ ДОМІШОК НА МІЦНІСТЬ АРБОЛІТУ ІЗ ЗАПОВНЮВАЧЕМ 3 КОСТРИ ЛЬОНУ
}

К-т техн. наук І.С. Казімагомедов, аспір. Лобанова А.В

ИССЛЕДОВАНИЕ ВЛИЯНИЯ ХИМИЧЕСКИХ ДОБАВОК НА ПРОЧНОСТЬ
АРБОЛИТА С ЗАПОЛНИТЕЛЕМ ИЗ КОСТРЫ ЛЬНА

К-т техн. наук И.Э. Казимагомедов, аспир. Лобанова А.В

\section{STUDY OF INFLUENCE OF CHEMICAL ADDITIVES ON THE STRENGHT ARBOLIT WITH FLAX OF WASTE FILLERS}

Cand. of techn. sciences I.E. Kazimagomedov, postgraduate A.V. Lobanova

У роботі розглянуто питання ефективності використання хімічних домішок для отримання арболітових конструкційно-теплоізоляційних стінових виробів із заповнювачем 3 костри льону. Звичайна вібрачія при формуванні виробів з арболіту малопридатна через легку вагу органічного заповнювача і його пружних властивостей. Для вирішення даної проблеми в роботі також розглянуто питання ущуільнення арболітової суміші за допомогою способу трамбування.

Ключові слова:арболіт, костра льону, хімічні домішки, міџність при стисненні, міциність при вигині.

В работе рассмотрен вопрос эффективности использования химических добавок для получения арболитовых конструкционно-теплоизолящионных стеновых изделий $c$ заполнителем из костры льна.Обычная вибрация при формовании изделий из арболита малопригодна из-за лёгкого веса органического заполнителя и его упругих свойств. Для решения данной проблемь в работе также рассматривается вопрос уплотнения арболитовой смеси при помощи трамбования.

Ключевые слова: арболит, костра льна, химические добавки, прочность при сжатии, прочность при изгибе.

The flax of waste are considered as material for aggregates for therma linsulation. Structural insulated building blocks are recommended for effective civil and industrial construction. Problems of using chemical additives to wall details of arbolit with flax of waste fillers are described. Usual vibration during forming arbolit products is not be used because of the low weight an organic filler and his elastic properties.To solve this problem also discusses the seal arbolit mixture with compacting.

Keywords:Arbolit, flax of waste, chemical additives, compressive strength, flexural strength.

\section{Введение}

В настоящее время перед отечественным производством стеновых изделий стоят задачи по восстановлению и увеличению объемов производства, повышению качества и конкурентоспособности выпускаемой продукции, снижению токсичности и материалоемкости строительного производства, организации эффективной переработки образующихся отходов. Решение этих задач основано на разработке новых и совершенствовании имеющихся технологий современногопроизводства композиционных материалов на основе органических заполнителей.

Основной путь повышения эффективности производства композиционных материалов - разработка ресурсосберегающих технологий, предусматривающих использование всех возможных отходовдеревообработкии перерабатывающих производств сельского хозяйства. Отходы переработки 
сельскохозяйственных культур (льна, конопли, зерновых культур и т.п.) могут являться дешевым сырьем для производства конструкционно-теплоизоляционных

стеновых изделий высокого качества.

В последние годы наметился рост производства и переработки льна, обладающего повышенными экологическими и эксплуатационными качествамикак в Украине, так и во всем мире.

Костра льна эффективна для переработки в материалы различного назначения, что обусловлено особенностями ее физико-химического строения и дешевизной.

Стебли льна при выделении волокна в процессах мятья и трепания разрушаются, а отпадающие одревеснелые части образуют костру. Размеры этих частиц колеблются от 1 до 10 мм по длине, чаще всего встречаются частицы длиной порядка 5 мм. Толщина колеблется в пределах $0,3 \ldots 1,5$ мм. Средняя

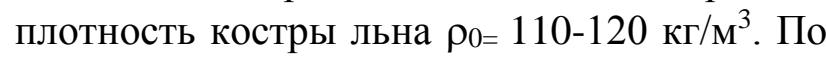
химическому составу сходнас древесиной.

В льняной костре содержится до $45-58 \%$ целлюлозы, лигнина 21-29\%, пентозанов 23-26\% [1]. Применение костры льна в производстве стеновых изделий с минеральными вяжущими, например, с цементом, вполне оправдано только при условии снижениивоздействия так называемых «цементных ядов» на процессструктурообразования

материала.Поэтому при проектировании состава арболита для стеновых изделий следует внимательно подходить к подбору различных химических добавок, используемых в качестве минерализаторов.

Актуальность работы.Перспективой развития совершенствования современной строительной и промышленной индустрии является создание новых строительных материалов с высокими эксплуатационнымии экономическими характеристиками. Для решения данной проблемы необходимо комплексно использовать отходы различных видов. В частности, использование костры льна позволит существенно снизить себестоимость строительных материалов и изделий из них, тем самым снизив экологические отходы за счет сокращения объемов неиспользуемой древесины.

Основной задачей, стоящей перед производством арболита, является подбор химических добавок с максимальным действием на экстрактивные вещества и сахара, содержащиеся в органическом заполнителе, которые отрицательно влияют на процесс схватывания и твердения вяжущего.

\section{Основная}

часть.

производственных условиях число компонентов и вид добавок определяют исходя из конкретных условий: качества применяемого древесного заполнителя, назначения и условий эксплуатации изделий и конструкций. Технология арболита в основном включает те же операции, что и технология обычного бетона на пористых заполнителях. Однако целлюлозный заполнитель как специфический материал вносит свои коррективы во все технологические операции.

Важнейшим из технологических факторов, влияющие на физикомеханические свойства арболита и экономические показатели его производства - способ формования и уплотнения. От него зависит макроструктура и ее характеристики такие, как средняя плотность, тепло- и звукопроводимость, влагостойкость.

Поскольку арболитовая смесь почти на 90 процентов по объему состоит из древесного заполнителя, в процессе формования и уплотнения смесь также как и древесина проявляет упругопластичные свойства. Поэтому процесс уплотнения арболитовой смеси сопровождается распрессовкой отформованного изделия после снятия приложенной нагрузки. Древесно-цементные смеси до уплотнения содержат значительное количество воздуха между частицами заполнителя, поэтому характеризуются очень высокой сжимаемостью. В зависимости от средней плотности формуемых изделий и фракции древесного заполнителя коэффициент уплотнения для арболитовой смеси изменяется от 1,2 до 1,8 . Это в свою очередь влияет на величину распрессовки, для 
устранения последствий которой часто, особенно в случае вибропрессования, при уплотнении арболитовой смеси применяют разборные формы с фиксирующими крышками.

Обычная вибрация при формовании изделий из арболита малопригодна из-за легкого веса органического заполнителя и его упругих свойств. Частично эти препятствия в формовке арболита можно обойти с помощью трамбования смеси.

В работе был произведен ряд экспериментов по изготовлению арболитовых образцов размерами 100x100x400 мм методом трамбования с использованием костры льна как основного заполнителя и различных химических добавок. В качестве вяжущего использовался портландцемент марки ПЦ500Н. Изменение процентного содержания и вида химических добавок, позволило получить образцы с высокими физико-механическими характеристиками (см. табл.1).
Отформованные образцыисследовали на прочность при сжатии и изгибе, при различных сроках выдержки арболитовой смеси в формах при температуре $18-20^{\circ} \mathrm{C}$ в естественных условиях.

Анализ данных из табл.1показал что состав №14, в котором использовалось жидкое стекло, а также водный раствор насыщенный минеральной добавкой, позволяет повыситьфизико-механические характеристики в 3 раза(300\%), по отношению к контрольным составам №7 и №8.

\section{Вывод:}

Исследованные образцы, по показанию средней плотности $\left(\rho_{\circ}=630\right.$ $\left.\kappa г / \mathrm{M}^{3}\right)$,и по прочности при сжатии могут быть применены в производстве конструкционно-теплоизоляционных арболитовых блоков для наружных стен промышленных, жилых

сельскохозяйственных зданий.

Таблица 1

Физико-механические характеристики арболита на основе костры льна

\begin{tabular}{|c|c|c|c|c|c|c|c|c|}
\hline \multirow[t]{2}{*}{$\begin{array}{c}\text { № } \\
\Pi / \Pi\end{array}$} & \multirow[t]{2}{*}{$\begin{array}{c}\text { Наименование состава и расход } \\
\text { материалов на } 1 \mathrm{~m}^{3} .\end{array}$} & \multirow[t]{2}{*}{ 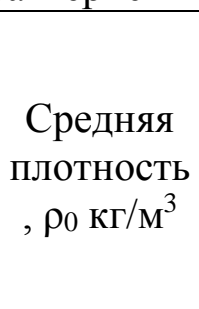 } & \multicolumn{3}{|c|}{ 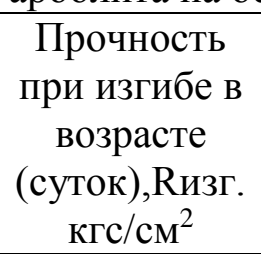 } & \multicolumn{3}{|c|}{ 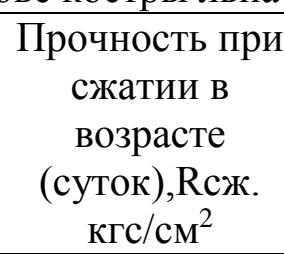 } \\
\hline & & & 7 & 14 & 28 & 7 & 14 & 28 \\
\hline 1. & $\begin{array}{l}\text { Безгипсовый цемент - } 350 \text { кг. } \\
\text { Костра льна - } 250 \text { кг } \\
\text { Вода }-360 \text { кг } \\
\text { Поташ } 2 \% \text { от массы БЦ } \\
\text { ЛСТ }-1 \% \text { от массы БЦ } \\
\mathrm{Al}_{2} \mathrm{SO}_{4}-2 \% \text { от массы БЦ }\end{array}$ & 640 & 3 & 10 & 11 & 4 & 9 & 10 \\
\hline 2. & $\begin{array}{l}\text { Безгипсовый цемент - } 350 \text { кг. } \\
\text { Костра льна - } 250 \text { кг } \\
\text { Вода }-360 \text { кг } \\
\text { Поташ } 2 \% \text { от массы БЦ } \\
\text { ЛСТ }-1 \% \text { от массы БЦ } \\
\text { Жидкое стекло - } 2 \% \text { от массы } \\
\text { БЦ }\end{array}$ & 630 & 3 & 8 & 9,4 & 4 & 9 & 10 \\
\hline
\end{tabular}




\begin{tabular}{|c|c|c|c|c|c|c|c|c|}
\hline \multicolumn{9}{|c|}{ Продовження таб. } \\
\hline 3. & $\begin{array}{l}\text { Безгипсовый цемент - } 350 \text { кг. } \\
\text { Костра льна - } 250 \text { кг } \\
\text { Вода }-360 \text { кг } \\
\text { Поташ } 2 \% \text { от массы БЦ } \\
\text { ЛСТ }-1 \% \text { от массы БЦ } \\
\mathrm{CaCl} 2-2 \% \text { от массы БЦ }\end{array}$ & 620 & 3 & 8 & 9,4 & 4 & 8 & 10 \\
\hline 4. & $\begin{array}{l}\text { Безгипсовый цемент - } 350 \text { кг. } \\
\text { Костра льна - } 250 \text { кг } \\
\text { Вода }-360 \text { кг } \\
\text { Поташ }-1 \% \text { от массы БЦ } \\
\text { CaCl } 2-4 \% \text { от массы БЦ }\end{array}$ & 650 & 4 & 9 & 9 & 4 & 9 & 10 \\
\hline 5. & $\begin{array}{l}\text { Безгипсовый цемент - } 350 \text { кг. } \\
\text { Костра льна- } 250 \text { кг } \\
\text { Вода - } 360 \text { кг } \\
\text { Поташ - } 1 \% \text { от массы БЦ } \\
\text { СаСl2- 2\% от массы БЦ } \\
\text { Жидкое стекло - } 2 \% \text { от массы } \\
\text { БЦ }\end{array}$ & 620 & 10 & 9,4 & 8 & 8 & 10 & 11 \\
\hline 6. & $\begin{array}{l}\text { Безгипсовый цемент - } 350 \text { кг } \\
\text { Костра льна - } 250 \text { кг } \\
\text { Вода }-360 \text { кг } \\
\text { Поташ - } 1 \% \text { от массы БЦ } \\
\text { Жидкое стекло - } 2 \% \text { от массы } \\
\text { БЦ }\end{array}$ & 630 & 10 & 9 & 8 & 10 & 10 & 11 \\
\hline 7. & $\begin{array}{l}\text { Портландцемент ПЦ500Н - } 350 \\
\text { кг } \\
\text { Костра льна }-250 \kappa г ~ \\
\text { Вода }-360 \kappa г ~ \\
\text { СаCl2- 4\% от массы } \\
\text { ПЦ(контрольный состав) }\end{array}$ & 640 & 7 & 7,5 & 8 & 7 & 8 & 10 \\
\hline 8. & $\begin{array}{l}\text { Портландцемент ПЦ500Н - } 350 \\
\text { кг } \\
\text { Костра льна - } 250 \text { кг } \\
\text { Вода - } 360 \text { кг } \\
\text { Жидкое стекло- 4\% от массы } \\
\text { ПЦ(контрольный состав) } \\
\end{array}$ & 630 & 7 & 9 & 13 & 7 & 9 & 12 \\
\hline 9. & $\begin{array}{l}\text { Портландцемент ПЦ500Н - } 350 \\
\text { кг } \\
\text { Костра льна - } 250 \text { кг } \\
\text { Вода }-360 \text { кг } \\
\text { СаСІ2-4\% от массы ПЦ } \\
\text { Жидкое стекло- } 4 \% \text { от массы } \\
\text { ПЦ }\end{array}$ & 650 & 7 & 9,4 & 11 & 7 & 8 & 10 \\
\hline 10. & 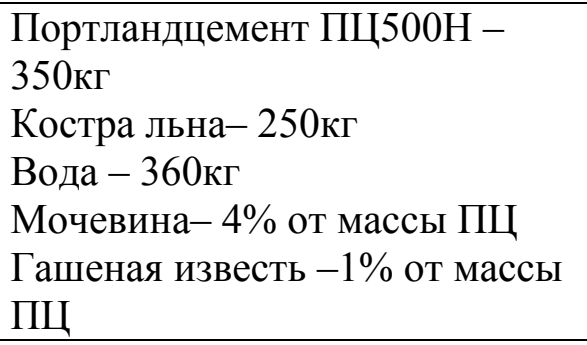 & 620 & 6 & 8 & 9 & 6 & 8 & 9 \\
\hline
\end{tabular}




\begin{tabular}{|c|c|c|c|c|c|c|c|c|}
\hline \multicolumn{9}{|c|}{ Продовження таб. } \\
\hline 11. & $\begin{array}{l}\text { Портландцемент ПЦ500Н - } \\
350 к г \\
\text { Костра льна - 250кг } \\
\text { Вода - 360кг } \\
\text { Sica- 1\% от массы ПЦ } \\
\text { Жидкое стекло-4\% от массы } \\
\text { ПЦ }\end{array}$ & 640 & 7 & 8 & 9 & 10 & 10 & 11 \\
\hline 12. & 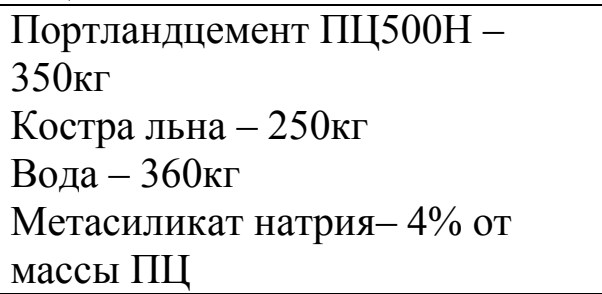 & 630 & 8 & 8 & 9 & 9 & 10 & 10 \\
\hline 13. & 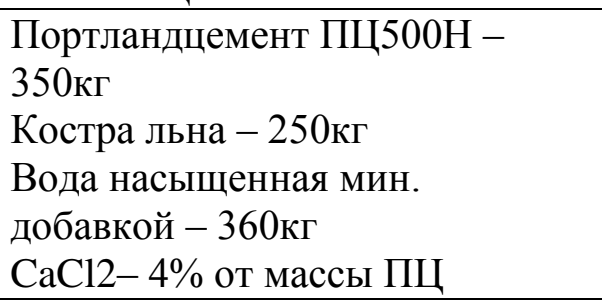 & 620 & 8 & 8 & 9 & 9 & 10 & 11 \\
\hline 14. & $\begin{array}{l}\text { Портландцемент ПЦ500Н - } \\
350 к г ~ \\
\text { Костра льна - 250кг } \\
\text { Вода насыщенная мин. } \\
\text { добавкой - 360кг } \\
\text { Жидкое стекло- 4\% от массы } \\
\text { ПЦ }\end{array}$ & 640 & 11 & 13 & 17 & 16 & 22 & 30 \\
\hline 15. & 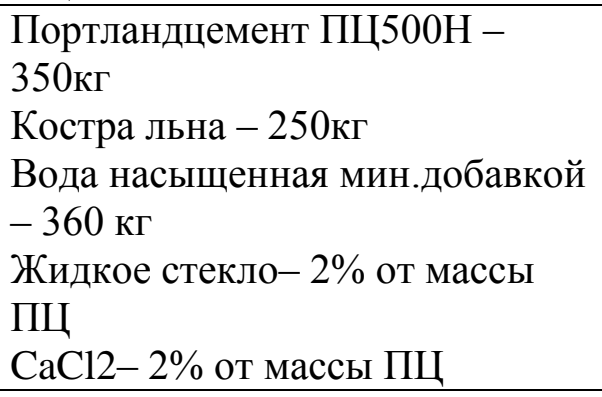 & 630 & 9 & 9 & 10 & 10 & 10 & 11 \\
\hline 16. & 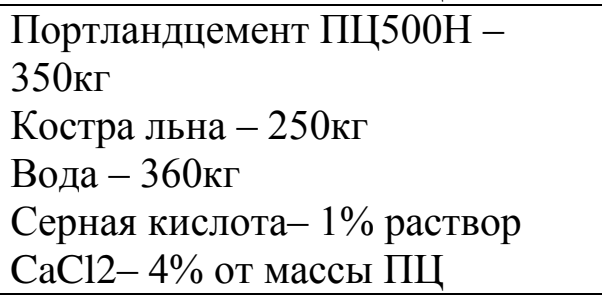 & 650 & 10 & 15 & 15 & 10 & 12 & 14 \\
\hline 17. & 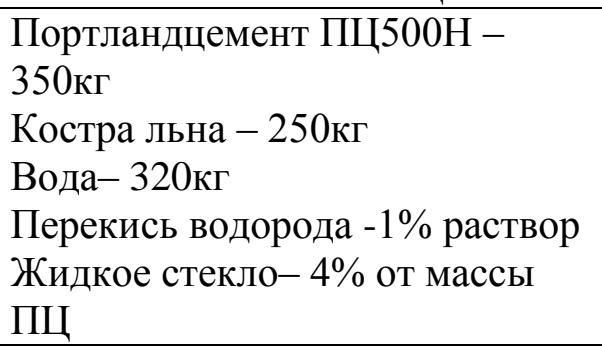 & 630 & 9 & 10 & 11 & 10 & 10 & 12 \\
\hline
\end{tabular}




\begin{tabular}{|c|c|c|c|c|c|c|c|c|}
\hline \multicolumn{9}{|c|}{ Продовження та } \\
\hline 18. & 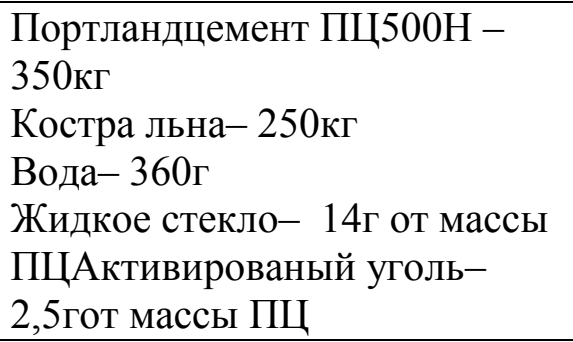 & 620 & 8 & 9 & 10 & 9 & 11 & 12 \\
\hline 19. & $\begin{array}{l}\text { Портландцемент ПЦ500Н - } \\
350 к г \\
\text { Костра льна - 250кг } \\
\text { Вода- 360кг } \\
\text { Кремнефтористый натрий 1\%- } \\
\text { от массы ПЦ } \\
\text { Жидкое стекло- 4\% от массы } \\
\text { ПЦ }\end{array}$ & 640 & 6 & 7 & 8 & 6 & 7 & 9 \\
\hline 20. & 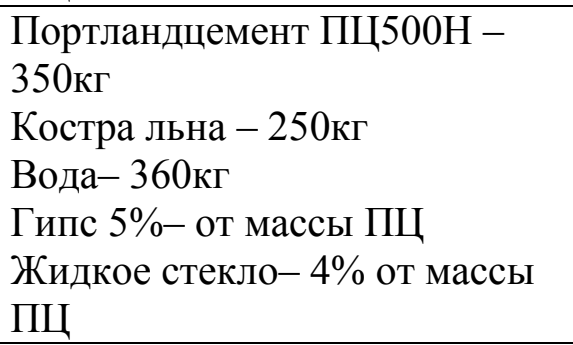 & 620 & 9 & 11 & 11 & 14 & 16 & 18 \\
\hline 21. & 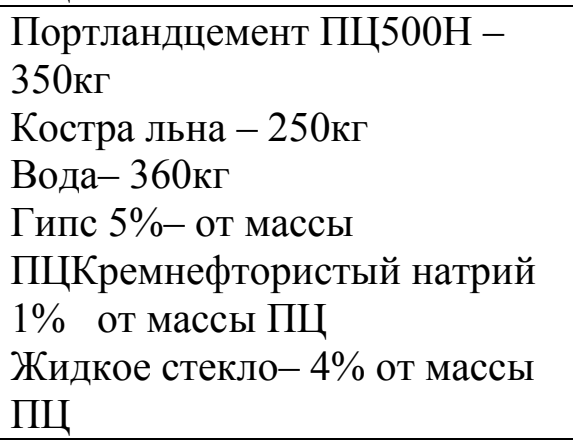 & 630 & 7 & 8 & 9 & 8 & 10 & 12 \\
\hline 22. & 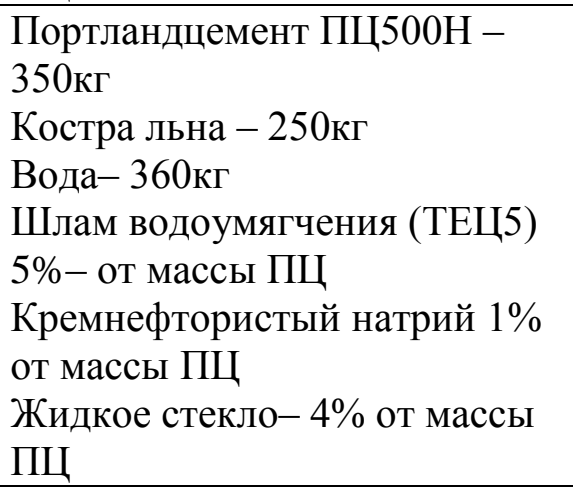 & 650 & 6 & 7 & 9 & 12 & 10 & 16 \\
\hline
\end{tabular}

\section{Список використаних джерел}

1. Казимагомедов И.Э.Эффективные стеновые блоки на основе костры льна. Казимагомедов И.Э., Лобанова А.В., Минатуллаев М.Б. Приоритетные направления науки и техники: сб. докладов Междунар. науч.практич. конф. Г. Пенза: ПГУАС, 2014.- 98-100 с.

2.Наназашвили И.Х. Структурообразование древесно-цементных композитов на основе ВНВ/ Бетон и железобетон. №12. М., 1991. С. 15-17.

3. Уголев Б.Н. Древесиноведение с основами лесного товароведения. - М: Лесная промышленность, 1986. - 386 с. 
4.Арболит на основе костры кенафа / Под ред. С.Л. Гринберг. Саратов, 1983.

5.Вондоловский А.Г., Казимагомедов И.Э., Подосинова В.Л. Арболитовые блоки на основекострыльна.//Науковийвісник будівництва, ХДТУБА, ХОТВ АБУ, 2012. - Вип.71. c.264-268.

6.Masazza F., Costa V., Barrilla A. Interaction between superplastificizers and calcium aluminate hydrates//I Am. Ceram. Soc. 1982.V. 65.N.4.-pp. 203-207.

7. Наназашвили И.Х. Строительные материалы из древесно-цементной композиции-2еперераб.идоп.-Л.: Стройиздат,1990.-415 с.

8. Арболит: Проблемы и перспективы/Ред.кол.: М.И. Клименко, В.В.Викулов, С.Л. Гринберг. Саратов, 1982. 78 с.

9.Прочность и деформативность арболита. Хорошун Л.П., Щербаков А.С.:-Киев, Наук. Думка, 1979.-192 с.

10. Комплексное использование древесины при производстве древесно-цементных материалов М.: Лесн. пром-ть, 1990-178с.

$$
\text { Рецензент д-р техн. наук, професор О.Г. Вандаловський }
$$

Лобанова Анастасия Валериевна асп. кафедры строительных материалов и изделий Харьковского национального университета строительства и архитектуры. Тел.0933508277. E-mail: asya3438529@mail.ru

Казимагомедов Ибрагим Эмирчубанович канд. техн. наук, кефедры строительных материалов и изделий Харьковского национального университета строительства и архитектуры. Тел. 706-20-73.

Lobanova Anastasiya Valerievna, Postgraduateat the Department of building materials and products Kharkiv National University of Civil Engineering and Architecture.Tel.0933508277 E-mail: asya3438529@mail.ru

Kazimagomedov Ibrahim, Candidate of Engineering Sciences, Associate Professor at the Department of building materials and products Kharkiv National University of Civil Engineering and Architecture.Tel. 706-20-73. 